\title{
Parsonage-Turner syndrome following coronavirus disease 2019 immunization with ChAdOx1-S vaccine: a case report and review of the literature
}

\author{
Bruno Kusznir Vitturi ${ }^{*}$, Marina Grandis ${ }^{2,3}$, Sabrina Beltramini ${ }^{4}$, Andrea Orsi ${ }^{5}$, Angelo Schenone ${ }^{2,3}$, \\ Giancarlo Icardi ${ }^{1,5}$ and Paolo Durando 1,6
}

\begin{abstract}
Background: Parsonage-Turner syndrome is an acute peripheral neuropathy that affects the upper brachial plexus region. Previously published reports demonstrate that the condition can be triggered by surgery, infection, autoimmune diseases, strenuous exercise, trauma, radiation, and vaccination. Parsonage-Turner syndrome has already been reported in three other patients who were vaccinated against coronavirus disease 2019.

Case presentation: We report the case of a 51-year-old Caucasian man without comorbidities who received the first dose of the ChAdOx1-S recombinant vaccine (Vaxzevria, AstraZeneca, Oxford, UK) against coronavirus disease 2019 and was diagnosed with Parsonage-Turner syndrome. A few days after getting vaccinated, the patient reported a progressive increase in pain in the region of vaccine administration. One month later, the shoulder pain was followed by symptoms of hypoesthesia and muscle weakness on abduction and elevation of the left upper limb. Neurological examination revealed an atrophy of the proximal muscles of the left upper limb, accompanied by paresis of the left deltoid, biceps brachii, triceps brachii, and infraspinatus muscles. Electroneuromyography carried out 3 months after the onset of symptoms showed signs consistent with brachial plexus neuritis. The adverse reaction has been properly reported to the Italian Pharmacovigilance System (Italian Medicines Agency_Agenzia Italiana del Farmaco.
\end{abstract}

Conclusion: The increased awareness of such association is essential for early identification and diagnosis and, thus, better clinical outcomes.

Keywords: Acute brachial neuritis, Adverse reactions, COVID-19, COVID-19 vaccines, Neuralgic amyotrophy, Parsonage-Turner syndrome

\section{Background}

Parsonage-Turner syndrome, also known as idiopathic neuralgic amyotrophy or brachial neuritis, is an acute peripheral neuropathy that affects the upper brachial plexus region. The incidence rate is 1 in 1000 per year.

*Correspondence: z_azul@hotmail.com

${ }^{1}$ Department of Health Sciences, University of Genoa, L.go R. Benzi, 10 (Building 3), 16122 Genoa, Italy

Full list of author information is available at the end of the article
The clinical phenotype usually includes excruciating pain in the proximal upper extremity followed by multifocal muscle weakness. Muscle atrophy and sensory symptoms may also occur [1]. Adhesive capsulitis, subacromial bursitis, facioscapulohumeral dystrophy, motor neuron disease, cervical radiculopathy, and entrapment neuropathies are generally the main differential diagnosis [2]. The etiology of Parsonage-Turner syndrome is still unclear, but it is thought to be an immune-mediated reaction against the brachial plexus nerve that occurs in original author(s) and the source, provide a link to the Creative Commons licence, and indicate if changes were made. The images or other third party material in this article are included in the article's Creative Commons licence, unless indicated otherwise in a credit line to the material. If material is not included in the article's Creative Commons licence and your intended use is not permitted by statutory regulation or exceeds the permitted use, you will need to obtain permission directly from the copyright holder. To view a copy of this licence, visit http://creativecommons.org/licenses/by/4.0/. The Creative Commons Public Domain Dedication waiver (http://creativeco mmons.org/publicdomain/zero/1.0/) applies to the data made available in this article, unless otherwise stated in a credit line to the data. 
genetically predisposed individuals. Previously published reports demonstrate that the condition can be triggered by surgery, infection, autoimmune diseases, strenuous exercise, trauma, radiation, and vaccination. Recently, brachial neuritis has been associated with severe acute respiratory syndrome coronavirus 2 (SARS-CoV-2) infection as well [3, 4]. Diagnosis is made based on the clinical history, physical examination, and electroneuromyography. Imaging examinations [computed tomography (CT) or magnetic resonance imaging (MRI)] can be useful to rule out other potential etiologies or when the electrophysiological study is inconclusive [5].

\section{Case presentation}

We report the case of a 51-year-old Caucasian man who received the first dose of the ChAdOx1-S recombinant (Vaxzevria, AstraZeneca, Oxford, UK) coronavirus disease 2019 (COVID-19) vaccine and was diagnosed with Parsonage-Turner syndrome. The patient had no history of chronic diseases and did not use any continuous medications. His immunization schedule was complete, and he had never had any major vaccine reactions. He denied any recent trauma or infectious disease. The first clinical manifestations occurred shortly after vaccine administration. Initially, the patient presented fever, malaise, and asthenia and, 4 days later, there was a progressive increase in pain in the region of vaccine administration, which made him self-medicate with paracetamol, nonsteroidal anti-inflammatory drugs (NSAID), and pregabalin. One month later, the patient developed symptoms of hypoesthesia and muscle weakness on abduction and elevation of the left upper limb. Neurological examination revealed atrophy of the proximal muscles of the left upper limb, accompanied by paresis of the left deltoid, biceps brachii, triceps brachii, and infraspinatus muscles. There were no changes in superficial and deep sensation, and there were no motor deficits in other segments of the body. All deep tendon reflexes were normoactive and symmetrical. The patient was always lucid, oriented, and collaborative. No sensory deficits, fasciculations, or pathological upper motor neuron signs were seen. There were neither meningeal signs nor alterations in any cranial nerve.

Electroneuromyography (ENMG) carried out 3 months after the onset of symptoms showed signs consistent with brachial plexus neuritis. There was mild to moderate peripheral neurological damage with signs of reinnervation in the region of the deltoid, biceps brachii, triceps brachii, infraspinatus, extensor pollicis longus and brevis, and first interosseous muscles. A reduction in the amplitude of the left axillary nerve action potential was also observed. The clinical manifestations, the onset of symptoms soon after vaccine administration, and the absence of a past significant medical history, together with the physical examination findings and the typical alterations in electroneuromyography, allowed us to establish the diagnosis of Parsonage-Turner syndrome. The adverse reaction has been properly notified to the Italian Pharmacovigilance System (Italian Medicines AgencyAgenzia Italiana del Farmaco (AIFA), https://www.aifa. gov.it/en/web/guest/home). The patient was treated with NSAID, pregabalin, and physiotherapy. Five months after the initial presentation, he presented a partial recovery, persisting only with local muscle weakness.

\section{Discussion}

Parsonage-Turner syndrome has already been reported in three other patients who were vaccinated against COVID-19 (Table 1) [6-8]. Patients aged between 35 and 51 years, and the time to onset of first symptoms ranged from 5 to 9 days after the first dose. In all patients, there were sensory symptoms and compatible pathological findings on electrophysiological study. The cases occurred after the administration of two different COVID-19 vaccines, suggesting that the syndrome can occur regardless of their mechanism of action.

There is no randomized controlled trial supporting an evidence-based approach to this syndrome, but it is generally accepted that current treatment may involve a combination of steroids, analgesics, and physiotherapy [9]. Due to the neuropathic nature of pain, the use of anticonvulsants can also be effective. Rehabilitation especially offers the possibility of recovery of motor function and should be encouraged early in association with pharmacological therapy, in order to obtain the best neurological outcomes in the medium and long term [9]. Most patients evolve with partial or full recovery at 3 years; however, it is noteworthy that more than $70 \%$ of patients may experience residual paresis [9]. Besides, among the clinical manifestations associated with a worse prognosis, the involvement of the phrenic nerve stands out.

At the time of the submission of this case report, there were more than 72 million doses of COVID-19 vaccines administered in Italy and three other cases of Parsonage-Turner syndrome reported as a vaccine adverse reaction to the Italian Medicines Agency-AIFA, one of which was associated with the ChAdOx1-S vaccine, one with the BNT162b vaccine, and another with the Ad26. COV.2 (Johnson \& Johnson/Janssen) vaccine. All of them presented similar clinical manifestations; a favorable recovery was reported in one case (BNT162b vaccine), a partial recovery was outlined in another case (Ad26. COV.2 vaccine), and no information about the clinical evolution was available in the case that occurred following immunization with the ChAdOx1-S vaccine. Thus, the present report is the first case reported from Italy, 


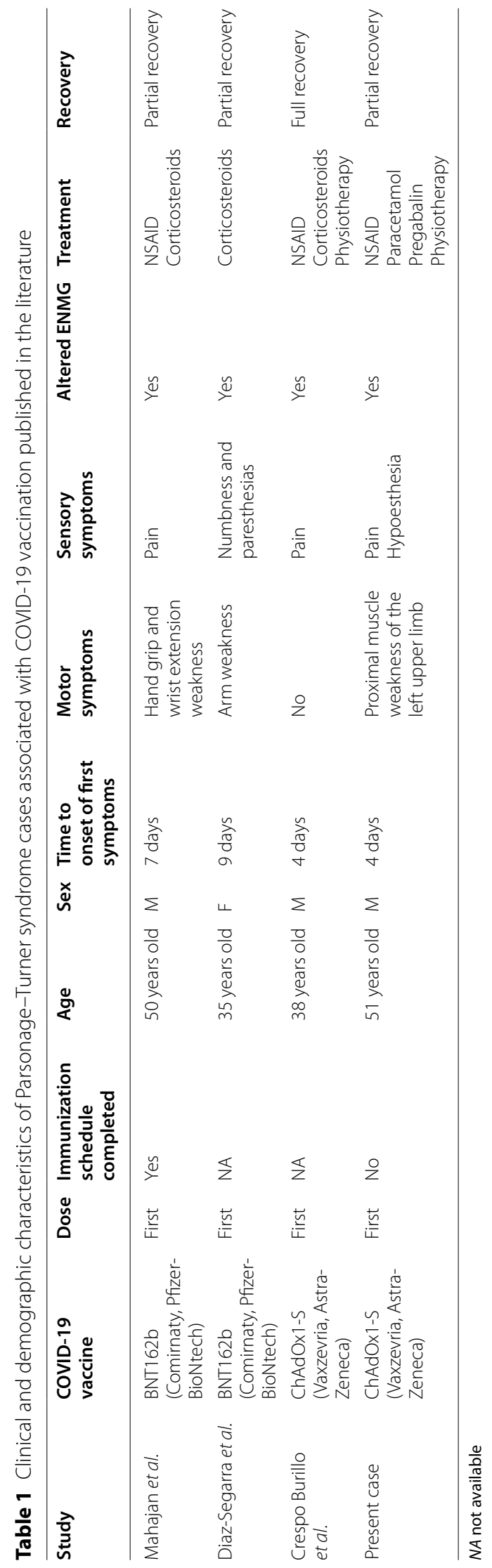


with complete clinical information available, and echoes the three cited case reports already published in the literature. Even so, it is important to mention that it is not possible to determine a causal link between the administration of the vaccine and the neurological syndrome.

\section{Conclusion}

Parsonage-Turner syndrome may be a rare adverse reaction to COVID-19 vaccines. It usually presents with intense pain in the proximal upper extremity followed by multifocal muscle weakness. This case report exemplifies that an increased awareness of such association is essential for an early identification and diagnosis and, thus, better clinical outcomes.

\section{Abbreviations}

AIFA: Agenzia Italiana del Farmaco; ENMG: Electroneuromyography; MRI: Magnetic resonance imaging; CT: Computed tomography; NSAID: Nonsteroidal anti-inflammatory drugs.

\section{Acknowledgments}

We are grateful to the authors of the other reports for confirming some information about their respective cases.

\section{Authors' contributions}

BKV searched and synthesized the data and wrote the main text. PD coordinated and revised the entire content of this report. MG, AS, and GI were responsible for monitoring and following up the patient. SB was the responsible for the notification of the case and for a review of other cases. All authors read and approved the final manuscript.

\section{Funding}

None.

\section{Availability of data and materials}

Not applicable.

\section{Declarations}

Ethics approval and consent to participate

Not applicable.

\section{Consent for publication}

Written informed consent was obtained from the patient for publication of this case report and any accompanying images. A copy of the written consent is available for review by the Editor-in-Chief of this journal.

\section{Competing interests}

The authors declare that they have no competing interests.

\section{Author details}

${ }^{1}$ Department of Health Sciences, University of Genoa, L.go R. Benzi, 10 (Building 3), 16122 Genoa, Italy. ${ }^{2}$ DINOGMI, University of Genoa, Genoa, Italy. ${ }^{3} \mathrm{Neu}-$ rology Unit, IRCCS Ospedale Policlinico San Martino, Genoa, Italy. ${ }^{4}$ Pharmacy Unit, IRCCS Ospedale Policlinico San Martino, Genoa, Italy. ${ }^{5}$ Hygiene Unit, IRCCS Ospedale Policlinico San Martino, Genoa, Italy. ${ }^{6}$ Occupational Medicine Unit, IRCCS Ospedale Policlinico San Martino, Genoa, Italy.

Received: 25 August 2021 Accepted: 1 November 2021

Published online: 13 December 2021

\section{References}

1. Ferrante MA, Wilbourn AJ. Lesion distribution among 281 patients with sporadic neuralgic amyotrophy. Muscle Nerve. 2017;55(6):858-61. https:// doi.org/10.1002/mus.25422.

2. van Alfen N. Clinical and pathophysiological concepts of neuralgic amyotrophy. Nat Rev Neurol. 2011;7(6):315-22. https://doi.org/10.1038/nrneu rol.2011.62.

3. Mitry MA, Collins LK, Kazam JJ, Kaicker S, Kovanlikaya A. Parsonage-Turner syndrome associated with SARS-CoV2 (COVID-19) infection. Clin Imaging. 2021;72:8-10. https://doi.org/10.1016/j.clinimag.2020.11.017.

4. Young Han C, Tarr AM, Gewirtz AN, Kaunzner UW, Roy-Burman P, Cutler TS, MacGowan DJ. Brachial plexopathy as a complication of COVID-19. BMJ Case Rep. 2021;14(3): e237459. https://doi.org/10.1136/ bcr-2020-237459.

5. Zhou L, Yousem DM, Chaudhry V. Role of magnetic resonance neurography in brachial plexus lesions. Muscle Nerve. 2004;30(3):305-9. https:// doi.org/10.1002/mus.20108.

6. Crespo Burillo JA, Loriente Martínez C, García Arguedas C, Mora Pueyo FJ. Amyotrophic neuralgia secondary to Vaxzevri (AstraZeneca) COVID-19 vaccine. Neurologia. 2021. https://doi.org/10.1016/j.nrleng.2021.05.002.

7. Diaz-Segarra N, Edmond A, Gilbert C, Mckay O, Kloepping C, Yonclas P. Painless idiopathic neuralgic amyotrophy after COVID19 vaccination: a case report. PM\&R. 2021. https://doi.org/10.1002/pmrj.12619.

8. Mahajan S, Zhang F, Mahajan A, Zimnowodzki S. Parsonage Turner syndrome after COVID-19 vaccination. Muscle Nerve. 2021;64(1):E3-4. https://doi.org/10.1002/mus.27255.

9. van Alfen N, van Engelen BG, Hughes RA. Treatment for idiopathic and hereditary neuralgic amyotrophy (brachial neuritis). Cochrane Database Syst Rev. 2009;2009(3): CD006976. https://doi.org/10.1002/14651858. CD006976.pub2.

\section{Publisher's Note}

Springer Nature remains neutral with regard to jurisdictional claims in published maps and institutional affiliations.
Ready to submit your research? Choose BMC and benefit from:

- fast, convenient online submission

- thorough peer review by experienced researchers in your field

- rapid publication on acceptance

- support for research data, including large and complex data types

- gold Open Access which fosters wider collaboration and increased citations

- maximum visibility for your research: over 100M website views per year

At BMC, research is always in progress.

Learn more biomedcentral.com/submissions 